\title{
EKSPERIMENTASI MODEL PEMBELAJARAN \\ KOOPERATIF MISSOURI MATHEMATICS PROJECT (MMP) DAN THINK PAIR SHARE (TPS) DENGAN PENDEKATAN SAINTIFIK PADA MATERI PERSAMAAN GARIS LURUS DITINJAU DARI KECERDASAN EMOSIONAL SISWA SMP NEGERI SE-KABUPATEN PEMALANG TAHUN PELAJARAN 2014/2015
}

\author{
Rizki Adeyanto ${ }^{1}$, Tri Atmojo Kusmayadi ${ }^{2}$ Riyadi $^{3}$ \\ ${ }^{123}$ Prodi Magister Pendidikan Matematika, FKIP Universitas Sebelas Maret Surakarta
}

\begin{abstract}
The aim of the research was to determine the effect of learning models scientific MMP, scientific TPS, scientific classical on mathematics achievement viewed from student Emotional Quotient (EQ). The objectives of research were to find out: 1) which one providing better learning achievement, scientific MMP, scientific TPS, or scientific classical. 2) which one having better learning achievement, students with high, medium, or low EQ. 3) in each learning models, which one having better learning achievement, students with high, medium, or low EQ. 4) in each EQ level, which one providing better learning achievement, scientific MMP, scientific TPS, or scientific classical. The type of the research was quasi experimental research using design factorial $3 \times 3$. The population was the students in grade VIII junior high school in a city of Pemalang. The size of the sample was 309 students. The hypothesis test used unbalance two ways analysis of variance. The conclusions of the research were as follows. 1) Scientific MMP provided better learning achievement than scientific TPS and scientific classical, while scientific TPS provided better learning achievement than scientific classical. 2) The students with high EQ had better learning achievement than medium and low EQ, while the students with medium EQ had better learning achievement than low EQ. 3) In scientific MMP, scientific TPS, scientific classical, the students with high EQ had better learning achievement than medium and low EQ, while the students with medium EQ had better learning achievement than low EQ. 4) At the students with high, medium, and low EQ, Scientific MMP provided better learning achievement than scientific TPS and scientific classical, while scientific TPS provided better learning achievement than scientific classical.

Keywords: scientific MMP, scientific TPS, scientific Classical, Emotional Quotient,n Achievement
\end{abstract}

\section{PENDAHULUAN}

Perkembangan ilmu pengetahuan dan teknologi telah mempengaruhi berbagai bidang kehidupan termasuk di dalamnya pendidikan. Matematika merupakan salah satu dasar terpenting untuk sains dan teknologi, karena mata pelajaran matematika dapat melatih siswa berpikir kritis, sistematis, dan logis. Namun dalam kenyataan saat ini, masih banyak siswa yang beranggapan bahwa matematika merupakan suatu pelajaran yang sangat sulit dan kebanyakan dari mereka tidak menyukai matematika.

Berdasarkan persentase daya serap matematika UN SMP tahun pelajaran 2013/2014, menunjukkan bahwa indikator menyelesaikan masalah yang berkaitan dengan persamaan garis lurus di Kabupaten Pemalang memperoleh nilai 37,80\%, Provinsi Jawa Tengah: 44,56\%, dan Nasional: 53,85\% (Balitbang, 2014). Berdasarkan data tersebut dapat dilihat bahwa perolehan nilai matematika UN SMP N tahun pelajaran 2013/2014 di 
kabupaten Pemalang pada indikator menyelesaikan masalah yang berkaitan dengan persamaan garis lurus lebih rendah dari perolehan nilai Nasional, sehingga mengindikasikan bahwa siswa masih kesulitan dalam menyelesaikan persamaan garis lurus. Salah satu faktor penyebab rendahnya prestasi belajar matematika siswa adalah model pembelajaran yang digunakan guru. Model pembelajaran matematika yang bersifat konvensional masih memberikan dominasi guru dan tidak memberikan akses bagi siswa untuk berkembang secara mandiri melalui penemuan dalam proses berpikirnya. Senada dengan model pembelajaran klasikal yang pembelajarannya terpusat pada guru. Akibatnya siswa kurang memahami materi yang disampaikan, dan siswa menganggap materi yang disampaikan sulit, serta membosankan, sehingga perlu diciptakan suasana belajar yang menyenangkan dan dapat meningkatkan prestasi belajar matematika.

Model pembelajaran kooperatif yang akan digunakan adalah model pembelajaran kooperatif Missouri Mathematics Project (MMP) dengan pendekatan saintifik dan Think Pair Share (TPS) dengan pendekatan saintifik karena kedua model pembelajaran ini membuat siswa belajar individu, kelompok, dan kerjasama dengan temannya. Missouri Mathematics Project (MMP) menurut Setiawan (2008:37), merupakan salah satu model pembelajaran yang terstruktur dengan pengembangan ide dan perluasan konsep matematika. Tujuan dari modelMissouri Mathematics Project(MMP) adalah dengan adanya tugas proyek dimaksudkan untuk memperbaiki komunikasi, penalaran, hubungan interpersonal, keterampilan membuat keputusan dan keterampilan menyelesaikan masalah (Rosani, 2004:5). TPS adalah model pembelajaran kooperatif yang dirancang untuk mempengaruhi pola interaksi siswa, dalam model ini terdapat tiga langkah pembelajaran sebagai ciri khas model kooperatif tipe TPS. Langkah yang pertama yaitu think (berpikir), pair (berpasangan), dan share (berbagi) (Trianto, 2009: 81). Hasil penelitian Wendy (2007) menunjukkan bahwa pembelajaran dimana penggunaan metode Think Pair Share (TPS) menimbulkan pengaruh yang positif sehingga menghasilkan prestasi yang baik.

Di sisi lain, siswa diberi model pembelajaran klasikal. Model pembelajaran klasikal merupakan suatu model pembelajaran yang masih menggunakan sistem yang biasa dilakukan oleh guru yaitu ceramah atau ekspositori. Dalam model pembelajaran klasikal guru memegang peranan utama dalam menentukan isi atau materi yang akan diajarkan. Dalam model ini pembelajaran berpusat pada guru. Di sini guru merupakan sumber utama bagi siswa dalam memperoleh pengetahuan. Pembelajaran dengan model ini membuat siswa cenderung pasif dalam proses belajar mengajar. Hal ini tentu tidak sesuai dengan kurikulum 2013 yang dalam proses pembelajarannya harus mengacu pada tiga ranah yaitu sikap, keterampilan, dan pengetahuan. Berdasarkan Permendikbud 
Nomor 81A Tahun 2013, proses pembelajaran pada Kurikulum 2013 menekankan pada dimensi pedagogik modern dalam pembelajaran, yaitu menggunakan pendekatan saintifik yang terdiri atas lima pengalaman pokok, diantaranya adalah mengamati, menanya, mencoba, mengolah, dan menyajikan. Oleh karena itu, guru mempunyai tanggung jawab untuk mewujudkan proses pembelajaran yang bermutu dan berkualitas agar siswa memperoleh prestasi belajar yang optimal. Dalam hal ini hendaknya guru menggunakan model pembelajaran yang lebih banyak melibatkan siswa untuk aktif dan mengaitkan materi pembelajaran dengan kehidupan sehari-hari.

Selain model pembelajaran, kecerdasan emosional siswa juga berpengaruh terhadap prestasi belajar siswa. Goleman (2003 36) menyatakan ada siswa yang mempunyai kemampuan intelektual di atas rata-rata tetapi memperoleh prestasi belajar yang relatif rendah, namun ada siswa yang kemampuan intelektualnya sedang, dapat meraih prestasi belajar yang relatif tinggi. Inteligensi bukan merupakan satu-satunya faktor yang menentukan keberhasilan seseorang, karena ada faktor lain yang mempengaruhi, diantaranya kecerdasan emosional. Kecerdasan emosional adalah kemampuan siswa untuk mengenali emosi diri, mengelola emosi diri, memotivasi diri sendiri, mengenali emosi orang lain (empati), dan kemampuan untuk membina hubungan (kerja sama) dengan orang lain. Hal ini senada dengan hasil penelitian yang dilakukan oleh Nwadinigwe and Obieke (2012: 395-401) menunjukkan bahwa ada hubungan positif antara kecerdasan emosional dan prestasi akademik sehingga perkembangan kecerdasan emosional akan meningkatkan prestasi akademik.

Penelitian ini kecerdasan emosional dibagi menjadi tiga kategori yaitu tinggi, sedang, dan rendah. Siswa yang mempunyai tingkat kecerdasan emosional tinggi maka dia mampu bangkit kembali dengan cepat dari suatu kegagalan dalam meraih prestasi, memiliki keterampilan berinteraksi dengan orang lain, mampu mengatur emosi untuk mencapai tujuan, serta cakap dalam kemimpinan. Siswa yang mempunyai tingkat kecerdasan emosional sedang terhadap matematika memiliki kesadaran diri, pengaturan diri, motivasi, empati, dan keterampilan sosialnya masih cenderung tenggelam, tetapi setelah pembelajaran dilakukan maka akan tumbuh perlahan, sedangkan siswa yang tingkat kecerdasan emosional rendah maka cenderung akan terlihat sebagai orang yang keras kepala, sulit bergaul mudah frustasi, tidak mudah percaya kepada orang lain, tidak peka dengan kondisi lingkungan, dan cenderung putus asa bila mengalami stress.

Dari uraian di atas dapat dirumuskan permasalahan penelitian ini adalah sebagai berikut: (1) manakah yang mempunyai prestasi belajar lebih baik, siswa yang dikenai model pembelajaran MMP saintifik, TPS saintifik atau klasikal saintifik (2) manakah yang mempunyai prestasi belajar lebih baik, siswa yang memiliki kecerdasan emosional 
tinggi, sedang atau rendah (3) pada masing-masing model pembelajaran, manakah yang mempunyai prestasi belajar matematika lebih baik, siswa yang memiliki kecerdasan emosional tinggi, sedang atau rendah (4) pada masing-masing tingkat kecerdasan emosional, manakah yang mempunyai prestasi belajar matematika lebih baik, siswa yang dikenai model pembelajaran MMP saintifik, TPS saintifik atau klasikal saintifik.

\section{METODE PENELITIAN}

Penelitian ini dilaksanakan di SMP Negeri se-Kabupaten Pemalang pada semester ganjil tahun pelajaran 2014/2015. Jenis penelitian adalah penelitian eksperimental semu (quasi experimental research) dengan rancangan $3 \times 3$ faktorial. Populasi dalam penelitian ini adalah siswa SMP Kelas VIII semester ganjil tahun pelajaran 2014/2015. Berdasarkan teknik pengambilan sampel tersebut, terpilih 3 sekolah sebagai sampel yaitu SMPN 2 Pemalang yang mewakili sekolah kelompok tinggi, SMPN 4 Taman yang mewakili sekolah kelompok sedang dan SMPN 1 Pemalang yang mewakili sekolah kelompok rendah. Sampel dalam penelitian ini berjumlah 309 siswa, yang terdiri dari 103 siswa pada kelas eksperimen I, 102 siswa pada kelas eksperimen II dan 104 siswa pada kelas kontrol.

Dalam penelitian ini terdapat dua variabel bebas yaitu model pembelajaran dan kecerdasan emosional siswa dan satu variabel terikat yaitu prestasi belajar matematika. Teknik pengumpulan data menggunakan metode dokumentasi dan metode tes. Metode dokumentasi digunakan untuk mengumpulkan data kemampuan awal siswa, metode tes digunakan untuk mengumpulkan data prestasi belajar dan kecerdasan emosional siswa. Instrumen yang digunakan dalam penelitian ini berupa tes objektif bentuk pilihan ganda pada materi persamaan garis lurus dan angket untuk membedakan siswa yang memiliki kecerdasan emosional tinggi, sedang atau rendah.

Uji coba instrumen angket kecerdasan emosional dan tes prestasi belajar matematika dilakukan di SMP Negeri 3 Pemalang dengan jumlah responden sebanyak 31 siswa. Untuk instrumen kecerdasan emosional dan tes prestasi belajar, mengacu pada kriteria yaitu validitas isi, daya pembeda ( $\mathrm{D} \geq 0,3)$, tingkat kesukaran $(0,3 \leq \mathrm{I} \leq 0,7)$ dan reliabilitas $\left(r_{11} \geq 0,7\right)$, dari 45 butir soal angket kecerdasan emosional siswa yang diujicobakan diperoleh 25 butir soal yang digunakan sebagai alat pengambil data kecerdasan emosional siswa dan dari 30 butir soal tes prestasi belajar matematika yang diujicobakan diperoleh 25 butir soal yang digunakan sebagai alat pengambil prestasi belajar matematika siswa. Uji prasyarat analisis yaitu uji normalitas menggunakan metode Lilliefors dan uji homogenitas menggunakn metode Bartlett, sedangkan uji 
hipotesisnya menggunakan uji anava dua jalan dengan sel tak sama yang dilanjutkan dengan uji komparasi ganda dengan metode Scheffe' jika hipotesis nol ditolak.

\section{HASIL PENELITIAN DAN PEMBAHASAN}

Setelah dilakukan uji keseimbangan untuk mengetahui kemampuan awal masingmasing populasi adalah sama, selanjutnya dilakukan uji hipotesis penelitian. Rerata masing-masing sel dan rerata marginal dapat dilihat pada Tabel 1.

Tabel 1 Rerata Masing-Masing Sel dan Rerata Marginal

\begin{tabular}{lcccc}
\hline \multirow{2}{*}{ Model Pembelajaran } & \multicolumn{2}{c}{ Kecerdasan Emosional Siswa Terhadap } & Rerata \\
& Tinggi $\left(\mathrm{b}_{1}\right)$ & $\begin{array}{c}\text { Matematika } \\
\text { Sedang }\left(\mathrm{b}_{2}\right)\end{array}$ & Rendah $\left(\mathrm{b}_{3}\right)$ & Marginal \\
\hline MMP saintifik $\left(\mathrm{a}_{1}\right)$ & 91,52 & 70,77 & 59,69 & 71,61 \\
TPS saintifik $\left(\mathrm{a}_{2}\right)$ & 80,35 & 64,44 & 53,57 & 67,29 \\
Klasikal saintifik $\left(\mathrm{a}_{3}\right)$ & 70,13 & 62,25 & 47,36 & 62,23 \\
Rerata Marginal & 78,45 & 65,97 & 54,53 & \\
\hline
\end{tabular}

Tabel 2 Rangkuman Analisis Variansi Dua Jalan dengan Sel Tak Sama

\begin{tabular}{lcccccc}
\hline \multicolumn{1}{c}{ Sumber } & JK & $\mathbf{d k}$ & $\mathbf{R K}$ & $\mathbf{F}_{\text {obs }}$ & $\mathbf{F}_{\text {tabel }}$ & Keputusan \\
\hline Model (A) & 9641,759 & 2 & 4820.879 & 31,613 & 3.026 & $H_{O A}$ ditolak \\
KE (B) & 35724,758 & 2 & 17862,379 & 117,133 & 3,026 & $H_{O B}$ ditolak \\
Interaksi (AB) & 1462.674 & 4 & 365,668 & 2.398 & 2.402 & $H_{O A B}$ diterima \\
Galat & 45748,993 & 300 & 152,497 & - & - & - \\
Total & 92578,183 & 308 & - & - & - & - \\
\hline
\end{tabular}

Kesimpulan analisis variansi dua jalan dengan sel tak sama berdasarkan Tabel 2.

adalah (1) Pada efek utama antar baris (A), siswa yang dikenai dengan model pembelajaran MMP saintifik, TPS saintifik, dan klasikal saintifik memberikan efek berbeda terhadap prestasi belajar matematika siswa. (2) Pada efek utama antar kolom (B), kecerdasan emosional siswa tinggi, sedang, dan rendah memberikan efek berbeda terhadap belajar prestasi matematika. (3) Pada efek interaksi (AB),tidak terdapat interaksi antara model pembelajaran dan kecerdasan emsoional siswa terhadap prestasi belajar matematika siswa.

Dari hasil perhitungan anava diperoleh $H_{O A}$ ditolak, kemudian dilakukan uji komparasi rerata antar baris dengan metode Scheffe. Berikut disajikan rangkuman perhitungan uji lanjut rerata antar baris dalam Tabel 3.

Tabel 3 Rangkuman Hasil Komparasi Rerata Antar Baris

\begin{tabular}{cccccc}
\hline Komparasi & $H_{0}$ & $H_{1}$ & $\mathrm{~F}_{\text {obs }}$ & $2 \mathrm{~F}_{0,05 ; 2 ; 300}$ & Keputusan \\
\hline$\mu_{1 .} v s \mu_{2 .}$ & $\mu_{1 .}=\mu_{2 .}$ & $\mu_{1 .} \neq \mu_{2 .}$ & 6,26 & 6,05 & $H_{0}$ ditolak \\
$\mu_{2 .} v s \mu_{3 .}$ & $\mu_{2 .}=\mu_{3 .}$ & $\mu_{2 .} \neq \mu_{3 .}$ & 29,86 & 6,05 & $H_{0}$ ditolak \\
$\mu_{1 .} v s \mu_{3 .}$ & $\mu_{1 .}=\mu_{3 .}$ & $\mu_{1 .} \neq \mu_{3 .}$ & 8,66 & 6,05 & $H_{0}$ ditolak \\
\hline
\end{tabular}

Berdasarkan Tabel 3 dan rerata marginal pada Tabel 1, dapat disimpulkan bahwa prestasi belajar siswa yang diberi model pembelajaran kooperatif MMP saintifik lebih baik dari model pembelajaran kooperatif TPS saintifik dan model pembelajaran klasikal saintifik, model pembelajaran kooperatif TPS saintifik lebih baik dari model 
pembelajaran klasikal saintifik. Model pembelajaran kooperatif MMP saintifik dan TPS saintifik yang merupakan model pembelajaran yang menggunakan diskusi kelompok, hal ini sesuai dengan penelitian Lestari (2012), model pembelajaran kooperatif MMP selain mendorong siswa untuk berpartisipasi aktif dalam pembelajaran dan juga banyaknya latihan soal yang diberikan sehingga prestasi belajar lebih baik, hasil penelitian lainnya dari Morgan et al. (2010) yang menyatakan bahwa pembelajaran kooperatif dapat meningkatkan prestasi belajar peserta didik. Adanya pembelajaran kooperatif memungkinkan adanya kerjasama antar siswa di kelas, sehingga dapat saling membantu meningkatkan kemampuan masing-masing siswa.

Dari hasil perhitungan anava diperoleh $H_{O B}$ ditolak, kemudian dilakukan uji komparasi rerata antar kolom dengan metode Scheffe. Berikut disajikan rangkuman perhitungan uji lanjut rerata antar kolom dalam Tabel 4.

Tabel 4 Rangkuman Hasil Komparasi Rerata Antar Kolom

\begin{tabular}{cccccc}
\hline Komparasi & $H_{0}$ & $H_{1}$ & $\mathrm{~F}_{\mathrm{obs}}$ & $2\left(F_{0,05 ; 2 ; 300}\right)$ & Keputusan \\
\hline$\mu_{.1} v s \mu_{.2}$ & $\mu_{.1}=\mu_{.2}$ & $\mu_{.1} \neq \mu_{.2}$ & 56,64 & 6,05 & $H_{0}$ ditolak \\
$\mu_{.2} v s \mu_{.3}$ & $\mu_{.2}=\mu_{.3}$ & $\mu_{.2} \neq \mu_{.3}$ & 179,34 & 6,05 & $H_{0}$ ditolak \\
$\mu_{.1} v s \mu_{.3}$ & $\mu_{.1}=\mu_{.3}$ & $\mu_{.1} \neq \mu_{.3}$ & 42,64 & 6,05 & $H_{0}$ ditolak \\
\hline
\end{tabular}

Berdasarkan Tabel 4 dan rerata marginal pada Tabel 1, dapat disimpulkan bahwa prestasi belajar siswa yang memiliki kecerdasan emosional tinggi terhadap matematika lebih baik daripada kecerdasan emsoional sedang dan rendah terhadap matematika, kecerdasan emosional sedang terhadap matematika lebih baik daripada kecerdasan emsoional rendah terhadap matematika. Hal ini sesuai dengan penelitian yang dilakukan oleh Astuti (2009) menyimpulkan bahwa siswa yang mempunyai tingkat kecerdasan emosional tinggi menghasilkan prestasi belajar matematika yang lebih baik dibandingkan dengan siswa yang mempunyai tingkat kecerdasan rendah. Hasil penelitian lainnya dari Yundari (2012) yaitu prestasi belajar matematika siswa yang memiliki tingkat kecerdasan emosional tinggi lebih baik dibandingkan siswa yang memiliki tingkat kecerdasan emosional sedang atau rendah, dan prestasi belajar siswa yang memiliki tingkat kecerdasan emosional sedang lebih baik dibandingkan siswa yang memiliki tingkat kecerdasan emosional rendah.

Dari hasil perhitungan anava diperoleh $H_{O A B}$ diterima. Hal ini berarti tidak ada interaksi antara model pembelajaran dan kecerdasan emosional siswa terhadap prestasi belajar matematika, sehingga dapat disimpulkan pada siswa yang dikenai pembelajaran kooperatif MMP saintifik, TPS saintifik, dan klasikal saintifik prestasi belajar matematika siswa yang memiliki kecerdasan emosional tinggi lebih baik dibandingkan siswa yang memiliki kecerdasan emosional sedang dan rendah, serta prestasi belajar matematika siswa yang memiliki kecerdasan emosional sedang lebih baik dibandingkan siswa yang 
memiliki kecerdasan emosional rendah. Pada siswa yang memiliki kecerdasan emosional tinggi, sedang dan rendah prestasi belajar matematika siswa yang dikenai model pembelajaran kooperatif MMP saintifik lebih baik dibandingkan dengan siswa yang dikenai model pembelajaran kooperatif TPS saintifik dan pembelajaran klasikal saintifik, serta prestasi belajar siswa yang dikenai model pembelajaran TPS saintifik lebih baik dibandingkan dengan pembelajaran klasikal saintifik.

Hal tersebut sesuai dengan Burrowes dalam Brickman et al. (2009) menyebutkan bahwa pembelajaran kooperatif menekankan pada resitasi konten, tanpa memberikan waktu yang cukup kepada siswa untuk merefleksi materi-materi yang dipresentasikan, menghubungkannya dengan pengetahuan sebelumnya, atau mengaplikasikannya kepada situasi kehidupan nyata, sehingga pada siswa yang mempunyai kecerdasan emosional tinggi dan sedang terhadap matematika siswa terlibat aktif dalam diskusi, mengerjakan tugas kelompok dengan penuh tanggung jawab sehingga mampu mengkonstruksi pengetahuannya sendiri.

Nurhidayah (2011) menyimpulkan prestasi belajar matematika siswa yang memiliki kecerdasan emosional terhadap matematika tinggi lebih baik dibandingkan prestasi belajar matematika siswa yang memiliki kecerdasan emosional terhadap matematika sedang maupun rendah, dan prestasi belajar matematika siswa yang memiliki kecerdasan emosional terhadap matematika sedang lebih baik dibandingkan prestasi belajar matematika siswa yang memiliki kecerdasan emosional terhadap matematika rendah. Diperkuat oleh hasil penelitian Oemar Hamalik dalam Widayati (2009) dikatakan bahwa terdapat faktor-faktor yang mempengaruhi belajar siswa diantaranya adalah belajar dilakukan dalam suasana yang menyenangkan, siswa telah siap belajar, siswa mempunyai minat yang dapat mendorong siswa belajar lebih baik.

\section{SIMPULAN DAN SARAN}

Berdasarkan analisis data dari penelitian yang dilakukan, dapat disimpulkan sebagai berikut. (1) Prestasi belajar matematika siswa yang dikenai model pembelajaran kooperatif MMP saintifik lebih baik daripada model pembelajaran kooperatif TPS saintifik dan model pembelajaran klasikal saintifik, dan prestasi belajar siswa yang dikenai model pembelajaran kooperatif TPS saintifik lebih baik daripada siswa yang dikenai model pembelajaran klasikal saintifik. (2) Prestasi belajar matematika siswa yang memiliki kecerdasan emosional tinggi terhadap matematika lebih baik daripada siswa yang memiliki kecerdasan emosional sedang dan rendah terhadap matematika, dan prestasi belajar siswa yang memiliki kecerdasan emosional sedang terhadap matematika lebih baik daripada siswa yang mempunyai kecerdasan emosional rendah terhadap 
matematika. (3) Pada siswa yang dikenai model pembelajaran MMP saintifik, TPS saintifik, dan klasikal saintifik, prestasi belajar matematika siswa yang memiliki kecerdasan emosional tinggi lebih baik dibandingkansiswa yang memiliki kecerdasan emosional sedang dan rendah, serta prestasi belajar matematika siswa yang memiliki kecerdasan emosional sedang lebih baik dibandingkan siswa yang memiliki kecerdasan emosional rendah. (4) Pada siswa yang memiliki kecerdasan emosional tinggi, sedang, dan rendah, prestasi belajar matematika siswa yang dikenai model pembelajaran kooperatif MMP saintifik lebih baik dibandingkan siswa yang dikenai model pembelajaran kooperatif TPS saintifik dan model pembelajaran klasikal saintifik, serta prestasi belajar siswa yang dikenai model pembelajaran kooperatif TPS saintifik lebih baik dibandingkan siswa yang dikenai model pembelajaran klasikal saintifik.

Berdasarkan simpulan hasil penelitian di atas, penulis dapat memberikan beberapa saran yang dirangkum sebagai berikut. 1) Mengacu pada hasil penelitian ini, model pembelajaran MMP saintifik dan TPS saintifik menghasilkan prestasi belajar yang lebih baik daripada model pembelajaran klasikal saintifik. Melihat hal ini, guru mata pelajaran matematika disarankan untuk menggunakan model pembelajaran tersebut dalam pembelajaran matematika. 2) Dalam menerapkan model pembelajaran MMP saintifik dan TPS saintifik, diharapkan sebelumnya guru mempersiapkan dengan sebaik-baiknya dan memaksimalkan peran diskusi kelompok, agar proses pembelajaran dapat berlangsung dengan baik. 3) Guru hendaknya memperhatikan kecerdasan emosional siswa karena berpengaruh dalam prestasi belajar.

\section{DAFTAR PUSTAKA}

Astuti, D. I. 2009. Pengaruh Kecerdasan Emosional Terhadap Kinerja Perawat Rumah Sakit Adi Husada Undaan Weran Surabaya. Surabaya : Universitas Airlangga.

Brickman, P, Gormally, C, Armstrong, N, and Hallar, B. 2009. Effects of Inquiry-based Learning on Students Science Literacy Skills and Confidence. International Journal for the Scholarship of Teaching and Learning . 3 (2), pp 1-22.

Goleman, D. 2003. Emotional Intelligence. Terjemahan : T. Hermaya. Jakarta : Gramedia.

Lestari, S. 2012. Psikologi Keluarga : Penanaman nilai dan penanganan Konflik dalam keluarga. Jakarta : Kompas Gramedia.

Morgan, BM, Rosenberg, GP and Wells, L. 2010. Undergraduate Hispanic Student Response to Cooperative Learning. College Teaching Methods and Styles Journal. 6(1), pp.7-13.

Nurhidayah. 2011. Ilmu Prilaku Dan Pendidikan Kesehatan Untuk Keperawatan. Jakarta : USU Press 
Nwadinigwe, I.P., and Obieke, A. U. 2012. The Impact of Emotional Intelligence on Academic Achievement of Senior Secondary School Students in Lagos. Nigeria. Journal of Emerging Trends in Educational Research and Policy Studies (JETERAPS) , 3(4), pp. 395-401.

Rosani. 2004. Model-Model Pembelajaran Konstruktivis. Bandung: Alfabeta.

Setiawan. 2008. Strategi Pembelajaran Matematika SMA. Yogyakarta: PPPPTK.

Trianto. 2009. Mendesain Pembelajaran Kontekstual. Jakarta: Cerdas Pustaka Publisher.

Widayati, T.S. 2009. Efektivitas Model Pembelajaran Portofolio Terhadap Hasil BelajarMatematika Ditinjau dari Sikap Siswa Terhadap Matematika Kelas XI IPS SMA Negeri di Kabupaten Klaten Tahun Pelajaran 2008/2009. Tesis. Surakarta:Universitas Sebelas Maret. Tidak Diterbitkan.

Wendy, D. 2007. The Effects of using Think-Pair-Share during Guided Readin Lessons. Publiser : The University of Waikato. Diambil dari http://researchcommons. waikato.ac.nz/handle/10289/2233.

Yundari. 2012. Eksperimentasi Model Pembelajaran Koperatif Tipe Team Assisted Individualzation dan Teams Games Tournament Terhadap Prestasi Belajar Matematika Ditinjau Dari Tingkat Kecerdasan Emosional Peserta Didik MTs SeKabupaten Ngawi. Surakarta: Tesis Universitas Sebelas Maret. 